This item was submitted to Loughborough's Research Repository by the author.

Items in Figshare are protected by copyright, with all rights reserved, unless otherwise indicated.

\title{
Optimal charging of electric vehicles using a stochastic dynamic programming model and price prediction
}

\section{PLEASE CITE THE PUBLISHED VERSION}

https://doi.org/10.4271/2015-01-0302

\section{PUBLISHER}

(C) SAE International

\section{VERSION}

AM (Accepted Manuscript)

\section{PUBLISHER STATEMENT}

This work is made available according to the conditions of the Creative Commons Attribution-NonCommercialNoDerivatives 4.0 International (CC BY-NC-ND 4.0) licence. Full details of this licence are available at: https://creativecommons.org/licenses/by-nc-nd/4.0/

\section{LICENCE}

CC BY-NC-ND 4.0

\section{REPOSITORY RECORD}

Mody, Sagar M., and Thomas Steffen. 2018. "Optimal Charging of Electric Vehicles Using a Stochastic Dynamic Programming Model and Price Prediction”. figshare. https://hdl.handle.net/2134/34009. 


\title{
Optimal Charging of Electric Vehicles using a Stochastic Dynamic Programming Model and Price Prediction
}

\author{
S.Mody, T. Steffen \\ Loughborough University
}

\begin{abstract}
The idea of grid friendly charging is to use electricity from the grid to charge batteries when electricity is available in surplus and cheap. The goal is twofold: to avoid putting additional load on the electricity grid and to reduce the cost to the consumer. To achieve this, a smart meter and a tariff with variable electricity prices has to be in place. In Day Ahead tariff (DA), prices are announced in advance for the next day, and this information can be used to select the cheapest times to charge the battery by the required amount. The optimization method is very simple, and it only has to be run once per day. However, the balance of supply and demand is not fully known in advance. Therefore Real Time Pricing (RTP) tariff supplies electricity at spot market rate depending on the current balance. This makes the charging process less predictable because it adds a stochastic element, but it does offer the potential of higher savings if future prices can be predicted with a reasonable degree of accuracy.
\end{abstract}

This paper proposes an optimal controller based on a stochastic dynamic program (SDP), which predicts future price changes from available data. The controller takes into account price variability via a simple grid model that allows of unexpected price rises and a gradual return to a normal grid price. The DP algorithm has two variables, the state of charge $(\mathrm{SoC})$ and the current electricity cost. It traces the expected total cost based on the stochastic model and makes a decision 'to charge or not' to minimize the expected (average) total cost. The results show that in case of a positive probability of price rises, the time to charge is chosen slightly before the lowest expected cost during the night. This is a rational solution, because waiting longer does increase the risk of an unexpected price spike. In the trivial case of a zero probability of unexpected price rises, the solution converges to the one found by the previous deterministic optimization algorithm.

\section{Introduction}

Electric Vehicles (EV) are becoming more popular and abundant, as the requirement to reduce carbon and greenhouse emissions increases. Charging of EVs is a time and power consuming affair; the effects of which can be widespread on the Electricity Grid of the future. Electricity grids are going through a revolution as well in the aim to reduce the carbon footprint of generating energy. The smart grid vision is quickly spreading to all sectors of energy distribution and consumption that are currently dominated by fossil fuels. It will become important to align the transport and electricity sectors in order to maintain grid stability in the future; when grids are dominated by renewable generation, high power appliances (like EVs) and other problems which already exist.

Hybrid EV (HEV) have been mildly successful in the past decade with the major producer, Toyota (Prius) selling 2 million units by 2009 . Whilst it is widely accepted that market forces alone have not been able to make the EV a first choice for many consumers; government policy support, research to make EVs less expensive and economy Page 1 of 14 improvement will improve their market significantly [1][2]. Although, electric driving ranges are limited for all three HEV, Plugin Hybrid EV (PHEV) and pure EV (BEV); surveys have indicated that $47-55 \%$ of single vehicle usage in a single day is less than 20 miles, with $82-88 \%$ of vehicles travelling less than 60 miles [3]. Kang and Recker's 2009 [3] study concludes that it is possible to convert between $80 \%$ to $90 \%$ of daily mileage to electric when using PHEV with a 60 mile range in California; under the condition that both home and public place charging stations are in use. These numbers indicate that EVs are more feasible than previously thought. JP Morgan performed a study in 2009 which forecasted 11.28 million EVs worldwide by 2020 and $20 \%$ of the total cars sold in North America [4].

A change from ICEVs to EVs' main impact will be that on the already stressed electric grids. The batteries of these vehicles require long times and high power and currents for charging. For most domestic users, charging will take place overnight at their homes. Moreover, the tendency to plug the vehicle in as soon as they reach home is high. Other typical charging loads could be concentrated in office or public car parks depending on the actual use of the vehicle during the day. Studies like [5]-[9] highlight the impact of EVs on electricity distribution in the future, in elaborate detail.

The subsequent effect will be to electricity market: generation methods, infrastructure and prices in the future will change significantly. In most countries the industrial sectors are on wholesale electricity prices- buying electricity at lower rates during off-peak hours. There is a possibility for such 'spot-markets' even for domestic electricity consumers as is case in Portugal, Germany, some parts of continental Europe and a few states in the USA. In such markets, the consumers are encouraged to shift their electricity usage to off-peak hours through high-price updates/alerts either hourly or daily. Advances in 'Smart-Grid' technology can allow this elastic behavior from households, helping them to reduce costs.

The meter records hourly consumption and also alerts the consumers of the latest and future prices. The smart grid is being promoted and provided to consumers in the U.S.A. for some time now. Electric utility providers in California, Colorado, Florida, Illinois, Indiana, Ohio, Texas, Washington and some other states have already been introducing smart grids to many customers. There is also a strong financial incentive being provided for both smart grid research and introduction via the Energy Independence Act of 2007 and the US Stimulus Package of 2009 [10].

The state of Illinois is a good example where RTP has been available to customers since 2003. The RTP programs have been successful in reducing the participating consumers' electric usage and bills and shifting usage to non-peak times of the day [11]. The two electricity providers which allow the choice of RTP are Amaren and ComEd. Amaren's Power Smart Pricing (PSP) and ComEd's Residential Real Time Pricing (RRTP) programs have reduced their peak demand in the 
range of $15 \%$ and achieved participant bill savings between $10-15 \%$ [11].

The above discussion shows that there are two problems to consider: Firstly, it will be important to manage the electricity loads and peak demands due to user profile of EV charging. Some load may have to be shifted from peak times to others either by persuading or enforcing the consumer to charge earlier or later. Secondly, charging the vehicle without control might also be a disadvantage for the consumer due to the possibility of a future with RTP. However both these problems can be looked as an opportunity for EVs. The flexibility of charging time can be looked as an advantage for load shifting and when smart-grid infrastructure is in place, communication with it can not only allow automatic flexible charging but can also be used to provide electricity from the vehicle to grid (V2G).

The following paper progresses from the idea in [13] taking into consideration the need of more complex prediction methods to provide an optimal solution to the charging problem. The idea is to automatically manage the charging time once the vehicle is plugged in to provide a full charge when required but at the lowest cost (hence at low demand hours). This paper treats the EV charging problem as dynamic and stochastic. Therefore, a stochastic optimization algorithm is used to design a controller and the simulation results are presented towards the end. The subsequent advantage of this can be to the grid in a way of load shifting.

Firstly, a literature study explains the motivation and current research in this field. Then the optimal charging problem is explored based on time-discrete solution and then the dynamic problem is introduced. Secondly, a case is made for using stochastic optimization within a dynamic program (DP), to find an optimal solution to the 'when to charge?' problem. The approach is discussed, explained and connected to the grid model for price changes. The controller algorithm and assumptions are described with a typical user charging scenario (evening at home charging) for simulation purposes. Lastly, the results obtained from different simulation scenarios are presented, showing its validity, and a brief outlook to future work is discussed.

\section{Research Literature}

\section{Vehicle Driver Charging Behavior}

Morrow et al. [14] performed a study for the U.S Department of Energy on PHEV charging and infrastructure. They looked at two main charging scenarios- at night home charging and opportunity charging at public facilities. The conclusion was that there is a peak in EV charging during the evening when users plug-in at home between 19:00 and 23:00. Wang et al. [15] simulated four charging scenarios which included uncontrolled charging, delayed charging (to promote load shifting), smart charging and smart charging with demand response (where the charging is optimally controlled by the electricity distributor). They concluded that smart and delayed charging can significantly reduce the total cost of the system both on the electric and charging side.

Page 2 of 14

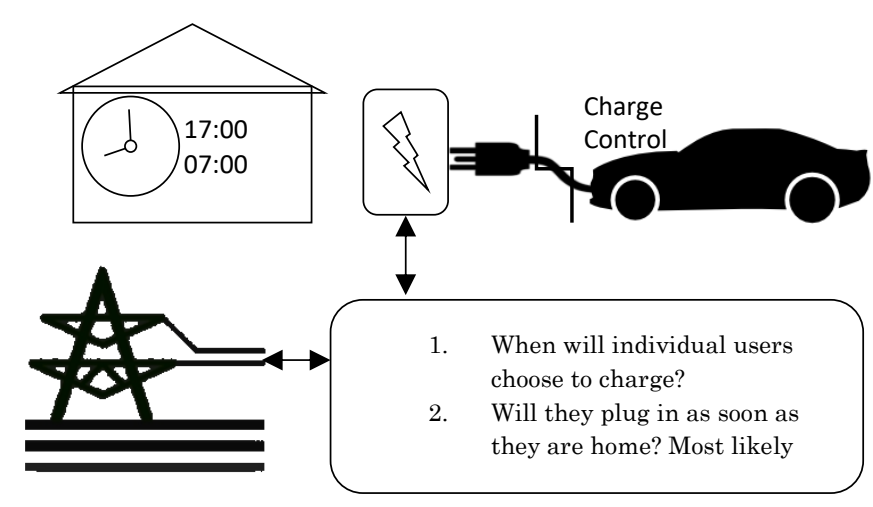

Figure 1: Charging Time of Concern

Kang and Recker [16] developed four theoretical scenarios of uncontrolled home charging, end of day travel charging, controlled (after $10 \mathrm{pm}$ ) charging and public infrastructure charging. They concluded that it was important for the electricity charging infrastructure's circuits to be upgraded for faster recharge times, which would allow more of the daily mileage to be electric. Clement and Hasen [17], Parks et al. [18] have also considered both the 'uncontrolled charging' and 'charging with a time delay scenario' in their studies. However, Clement and Hansen have suggested a 'coordinated controlled charging' scenario which should help minimize grid power losses. Mullan et al. [19] also took into account three scenarios: evening time charge (16:00-23:00), night time charge (22:00-7:30) and controlled night time charging using smart meters. They concluded that shifting the EV peak to later in the night can benefit the base-load utilization in Australia up to a limit governed by other effects in daily electricity-grid/transformer maintenance.

Most studies more or less conclude that the tendency to charge vehicles as soon as users reach home is extremely high. It will not be enough to allow users to charge their vehicles as they please without serious effects on the grid's health and power quality or simply the capacity. Most of them highlight the requirement of a 'smart' or 'controlled' way of charging the vehicles, the control of which may be shared between the user and the electricity provider. The charging behavior of users is difficult to predict, although it can be derived from their usage profiles. Charging locations and times will vary on user type, infrastructure and geography. For instance, a company fleet user may opt to do most charging at work, where infrastructure may be provided. However, an individual user would choose to charge both at home and public infrastructure. It is likely though, human behavior will propel users to plug-in their chargeable appliance as soon as they are home so 'it remains charged' by the time they need it. Studies like [20], [21], [19] and [22] conclude that the spike in charging requirements is pronounced between $5: 00 \mathrm{pm}$ and $7 \mathrm{am}$ based on the time majority vehicles arrive home. What is more interesting is that these studies are done in different geographical regions of the world and yet this time period is of concern whether or not the morning period at work may be of charging demand (assuming infrastructure is provided). The current study therefore assumes, the best time to study a simulation for this case would be between 17:00 and 7:00 am. Other assumptions and data sources are listed before the results are presented later in the paper. 


\section{Charging Solutions}

Studies on the effect of EV penetration to the electricity grid date back to the 1980s. In [23], Heydt discusses the effects on and of electric load management due to EV penetration. The study concludes that it is likely that charging will occur at peak demand times and some form of load management must be introduced to manage the additional EV charging load. Webster's review of electric infrastructure in the UK [24] concludes that in case of high EV penetration, it is likely that battery recharging times will coincide with peak electricity demand. Measures must be taken to avoid this although the electric networks can cope with the additional load. Both these authors consider the user profiles to be of primary impact on recharging times. In a much more recent study, Camus et al. [25] simulate a 2020 scenario of 2 million EVs in the Portuguese spot electricity market, considering different mixes of renewable power generation. They conclude that with low renewables and high cost, charging of EVs during peak times can lead to electricity prices of 17 Euro cents/KWh. This can be brought down to 7 Euro cents/KWh with off-peak charging and with higher renewables and low general costs, down to 5.6 Euro cents/KWh. Mahalik et al. [26] performed a simulation to realize EV impacts on the Illinois grid in 2020 and concluded that on-peak uncontrolled charging would require an additional $400 \mathrm{MW}$ unit to support the state's reserve margin. If off-peak and controlled charging is facilitated, no additional supporting grid would be needed.

Acha et al. [27] present a time coordinated optimal power flow (TCOPF) tool for distribution networks to decide on load control approaches for EVs in the future. The algorithms concentrate on showing different charging strategies to the electricity providers to see how they may have to change energy production to reduce carbon emissions and cost. They conclude for the UK context that, UK will need to introduce more renewables or non-carbon fuel mix to offset costs and emissions for high EV charging scenarios. Kristoffersen et al. [28] use a linear regression to minimize charging costs based on the Danish (Norpool) electricity market prices. The study made the assumption of an EV fleet controller who managed the participation of EVs during charging or providing electricity to the grid, based on fleet driving patterns and electricity prices. They concluded that EV driving patterns and hence charging time is highly flexible during the day but not from day to day.

Mody and Steffen [13] presented a study in 2013 describing the need to use automated control for 'optimal' charging of EVs. They observed that the increasing EV population will lead to electricity grid problem if it is treated like a normal appliance. It would be necessary to use a smart method to offset EV charging to lower demand hours by automatically charging the vehicle rather than let it charge instantly when it is plugged in. The paper presented a sub-optimal controller for automated charging based on real time tariffs provided by electricity grid distributors in Illinois (Chicago). The first conclusion was; if prices are known in advance (day-ahead pricing), the optimization only requires picking the cheapest time slots for charging the battery. Further savings can be made by using real time prices that are not known in advance. Although it becomes much more difficult to solve using price prediction strategies, the control can achieve optimal solutions (presented in this paper). The main conclusion was made from the results and case study of the simulation of the sub-optimal controller.

Scholer and Glynn [29] presented a charging solution in the technical paper (2014) with a similar idea to [13]. However, it was mainly a part of a series of technical papers written by the SAE PEV task force. The main theme of their paper was 'smart-charging standards' but their

Page 3 of 14 main conclusion also was; it is not necessary to charge the PEV immediately when plugged in and smart charging is required to balance the load and prevent problems in the local distribution circuit. They presented, a price-based smart charging idea based on RTP and smart grid communication very similar to the one presented by Mody and Steffen in [13]. It reacted to the price information and offset charging to lower demand times, still making sure that full charge was provided when needed.

Yunus, Parra and Reza [30] presented a paper on distribution grid impact of fast charging with a stochastic charging model (2011). The stochastic model they used was for a simulation of the effect of many PEVs loading the grid when charging at high power (fast charging). The model results led to a conclusion that widespread fast charging affects the quality of electricity supply and necessary actions need to be taken to continue the use and deployment of such stations for EV charging. In 2012, Druitt and Fruh [21] investigated a comprehensive model and simulation to quantify the integration of additional wind power and electric vehicles in the future electricity network. They suggested a stochastic model for both wind power generation and electricity price market. The study's aim however, was to investigate the role of a 'fleet' of EVs in a future grid to load management and energy storage potential (essentially $\mathrm{V} 2 \mathrm{G}$ ), with the integration of more wind power.

Zheng and Wang [31] proposed an aggregation model for large number of EVs charging, to control power fluctuation problems. They consider the randomness of the number of EVs charging at any time as a stochastic disturbance and employ a genetic algorithm to obtain these. They simulate this model for a parking lot scenario and show the stochastic feature of the charging characteristics. Their proposed charging strategy is to control (minimize) the influence of many EVs charging simultaneously to the grid power. They conclude their updateable model reduced power fluctuation level in the residential district where EVs in parking lot are being charged. However, their idea does not take into account the effect to $\mathrm{SoC}$ and user needs.

Although, there have been studies in the past few years (2010-2014) on future EV charging strategies; none of them have stressed on the need to find an optimal control solution for just the vehicle charging snapshot. Studies concentrate on the system view, including vehicleto-grid (which may be valid in the future and useful) and on assumptions about grid requirements regarding future regulations. Research so far has not been concentrated on isolating the 'snapshot' of charging a vehicle as a user might when they plug it in at home and won't control the time it is switched on. This is more of an issue which must be addressed imminently, as it may affect grids in the near future. Moreover, none of them stress on 'optimality' in finding the control inputs.

Hence, this paper explains the use of a stochastic dynamic approach to achieve optimality in the selection of charging power times. The advantage of this approach is that, it separates out the issue of charging hours and puts the confusion out of the user's mind, simultaneously avoiding 'instant charging' in case the cost is high, therefore preventing grid problems (high cost means high demand). Secondly, it provides a low overall cost (based on smart-grid information) thus automatically choosing hours when the electricity demand is low but at the same time predicting fluctuations that might occur and change the price. This prediction can help the control system to take a safer route and provide the charge at a low average cost (take penalty in certain situations), if the user needs the vehicle at a certain time. Most importantly, this control system is independent of changes that might occur on a system level; for example: all it requires is pricing data, 
time the charge is required (ToC) and level of charge (SoC). When the regulations for charging become clearer in the future, this system can fit in where required because parameters like 'charging-power' (likely to be regulated differently in the future) are variable in the control system. This means, their limits are pre-defined and the values can be picked when and as required rather than rigidly building a system which conforms to a single standard as it may exist today.

\section{The Charging Problem}

\section{Overview}

The problem of 'when to charge?' is complicated because of the number of parameters which could affect this decision. However, in essence it can be explained in two states in discrete-time. Two variables of concern to the user are $\mathrm{SoC}$ and ToC: i.e. how much charge is required and when is it required by? The two states in effect that would change as time goes along are grid cost (due to market forces/electricity demand) and $\mathrm{SoC}$ as a result of input. The final cost (which we want to minimize) is the output of the problem. The basic problem in [13] assumes day-ahead prices are perfect, therefore we know the price in advance. In 'spot' electricity markets retailers purchase electricity at the spot price and sell it on at heavily-regulated market prices. This leads to the problem of price-spikes when the spot price changes significantly within a short period of time. Therefore, real time electricity prices can change unexpectedly, so the assumption that they are known in advance has to be revisited. The basic problem is re-explained here in brief followed by its evolution to the dynamic problem of concern in the current study.

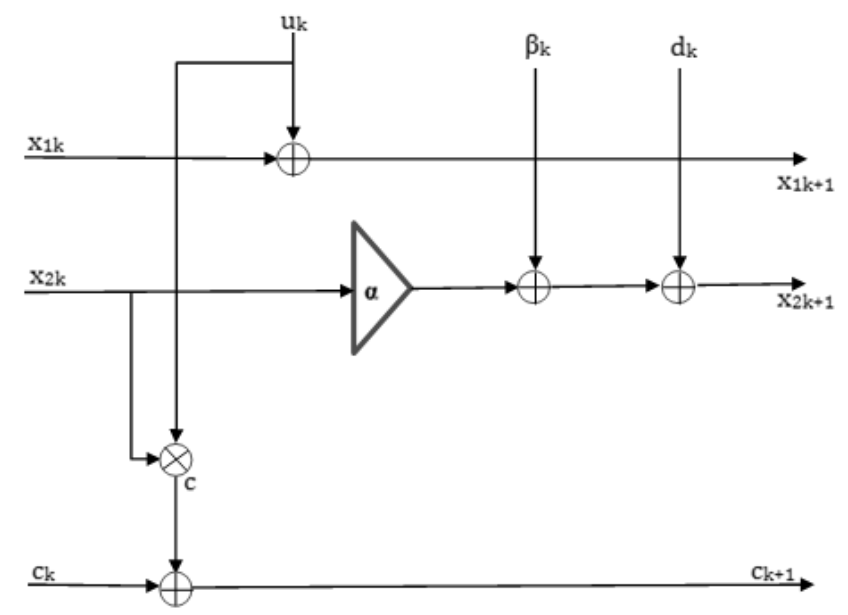

\section{Figure 2: Problem diagrammatic representation}

Figure 2 shows the problem block diagram in each time step $T s$ : $\boldsymbol{x}_{\boldsymbol{I}}$ is the battery SoC (state)

$\boldsymbol{x}_{2}$ is the grid cost (state)

$\boldsymbol{c}$ is the cost at each time step

$\boldsymbol{u}$ is the input (here: charge power)

$\boldsymbol{d}$ is the random disturbance causing price fluctuations

The problem has two distinct parts, one is the disturbance which changes the basic problem into a stochastic one. The deterministic or basic problem is symmetric. The summation of each time steps (Ts) evaluation leads to a final cost, say $\mathrm{J}_{\mathrm{N}}$. Where $\mathrm{N}$ is the final time-step.

\section{Basic Problem}

It has one control variable: the charging power $u$. The power is subject to two constraints: it cannot be negative and there is a constant maximum power $\bar{u}$ such that $u \in[0, \bar{u}]$.

The behavior of the system is determined by two separate dynamics: the battery state and the total cost. Both accumulate (integrate) over time and the only difference is the coefficient.

The battery state $X_{1}$ is an integral of the charge power over time:

$$
X_{1 k+1}=X_{1 k}+T u_{k}
$$

assuming that the self-discharge and charging losses are negligible.

The $\operatorname{cost} c_{k}$ is also an integral of the charge power but weighted by the current electricity price:

$$
c_{k+1}=c_{k}+T X_{2} u_{k}
$$

$c_{0}=0$. The price is a disturbance for the system, for the deterministic approach, it is assumed that it is known in advance.

The total number of steps $N$ to consider with $k=0 \ldots N$ are also defined in advance.

The basic optimal charging problem is defined by the cost function $J=$ $c_{N}$ representing the total electricity cost and the boundary condition $X_{1 N}=X_{1 \text { full }}$, which requires the battery to be fully charged at the end of the charging process.

Because no discharge is allowed, it is not necessary to impose limits on the charge state. The advantage of using this simple model is that the final state and cost can easily be calculated as:

$$
\begin{aligned}
& X_{1 N}=X_{1 \mid 0}+\sum_{0 \ldots N-1} T \cdot u \\
& c_{N}=\sum_{0 \ldots N-1} T \cdot X_{2} \cdot u
\end{aligned}
$$

\section{Self-Discharge and Resistive Losses}

Every battery has losses which are associated with both charge and discharging. It can be assumed that the efficiency of the battery pack therefore, will be less than $100 \%$ and the battery loses a certain part of its charge at every time step. This modifies the basic battery model:

$$
X_{1 \mid k+1}=\delta X_{1 \mid k}-\omega+\varphi T u_{k}
$$

Where $1-\delta$ is the relative discharge coefficient for each time-step, $\omega$ is the absolute discharge energy per time step and $\varphi$ is the charging efficiency. This leads to the following battery SoC:

$$
X_{1 N}=\delta^{N} X_{1 \mid 0}-\omega \sum_{0 \ldots N-1} \delta^{k}+\varphi \sum_{0 \ldots N-1} \delta^{N-k-1} T u_{k}
$$

Resistive losses within the battery (and the electricity supply) can be the dominating factor for charging losses. These resistive losses are proportional to the square of the current, assuming a constant voltage:

$$
u_{\text {in }}=u_{\text {out }}+R u_{\text {out }}^{2}
$$

where $R$ is the resistance normalized for the charging power. In terms of the optimization problem, the losses can be included either in the 
power going into the battery or in the cost of the electricity depending on whether $u_{\text {in }}$ or $u_{\text {out }}$ is the wanted variable. The latter produces an easier problem definition:

$$
c_{k+1}=c_{k}+T X_{2 k}\left(u_{k}+R u_{k}^{2}\right)
$$

These resistive losses in effect will tend have an influence in the decision to charge because practically the battery will only receive a part of the charging power. Secondly, losses are proportional to charging power, therefore they will be higher at higher charging powers (fast charging).

\section{Dynamic Problem and Random Disturbance}

The basic problem has a sub-optimal solution [13] but this is only applicable if the dynamics of decision problem are not taken into account. Once, the dynamic nature of the state variables are taken into consideration, the problem becomes a lot more complex. In this case, the varying nature of the grid-cost is important to the decision made by the controller and can be termed as the state which is affected by the stochastic disturbance (fig. 2). Therefore, this problem turns into a 2 state dynamic problem with a stochastic element.

By definition a dynamic programming problem is one which has both inputs and outputs which change dynamically with time [32]. This problem fits perfectly to this definition because we don't want to view the decision of 'when to charge' in isolation. The time varying grid cost (and potential unpredictable disturbance) make the decision requirement dynamic. Dynamic programming helps to balance the trade-off between low present cost and need for reduction of high future costs. Taking figure 2 as a guide; the ultimate aim is to minimize the summation of $c$ (from each time step) and the final $c_{N}$.

The problem with state $X_{2}$ is its dependence on the random disturbance $d$ whose nature is therefore, stochastic. The disturbance basically describes price 'spikes' or fluctuations which can change the trajectory of grid-cost and is dependent on market forces and electricity demand. The nature of the electricity market (purchase and sale) leads to unpredictable real time costs. This is what causes the difference between day-ahead prices and real-time prices when a smart-grid and smart-metering tariff is in question. By adding the stochastic element to the dynamic program, a solution for price prediction in context of EV charging (to try and minimize final cost) can be obtained as explained in further sections.

\section{New Grid Cost Model and Possible approaches}

To describe this nature of the electricity grid we can call the price 'spikes' as events and associate a probability to the occurrence of these events. Describing the cost model as a standard first order linear process where:

$\boldsymbol{d}$ is an uncorrelated random variable with a normal distribution. It can be possible to define this as Gaussian and may make solutions more accurate but this needs to be tested after the simulation stage

$\boldsymbol{c}_{\boldsymbol{k}+\boldsymbol{1}}$ is the cost (calculation for time-step $k+1$ )

$\boldsymbol{\alpha}$ is the decay factor can be calculated by performing a correlation of the hourly prices

$\boldsymbol{\beta}$ is the disturbance factor can be calculated by the difference in the hourly prices

$\boldsymbol{P}_{\boldsymbol{e v}}$ is the probability of an event occurring

Page 5 of 14 $\boldsymbol{\gamma}$ is the effect of an event

We get:

$$
c_{k+1}=\left\{\begin{array}{c}
\alpha c_{k}+\beta_{k} \cdot d \mid \text { no event }\left(d \geq P_{e v}\right) \\
\alpha c_{k}+\beta_{k} \cdot d+\gamma \mid \text { event }\left(d<P_{e v}\right)
\end{array}\right.
$$

The optimal solution, is defined as providing the lowest expected cost $E\langle J\rangle$ of deciding whether to charge or not, is difficult to find. There can be several approaches to solving the problem but some of the standard solutions are difficult to apply. The standard model predictive control (MPC) approach is difficult to justify because the applicability of limits is no longer a discrete decision, but a stochastic event. The limits then turn the Gaussian probability distributions into piecewise Gaussian distributions, which are difficult to handle numerically.

This problem is of a much more complicated nature, because it asks the question whether it is better to charge at current electricity prices, or to wait for them to fall. The central question "are prices going up or down?" lies at the heart of economic markets and market theory, and it cannot be answered with certainty. Typical solutions can be based on the Hamilton-Jacobi-Bellman (HJB) equation, which traces the expected cost based on a stochastic pricing model. Approximating and solving this equation is numerically challenging and it may not be practically feasible with any degree of accuracy. Theoretical advances are being made in a number of fields. MPC with stochastic weight models can be used [33] (most stochastic MPC approaches will consider only stochastic limits, not weights). On the other hand dynamic programming (usually involving quantization) and mixed integer algorithms can help to find the expected cost benefit of charging at specific times [34] with relative ease and accuracy. Finally there are a number of industry specific approaches coming from operations research, that deal with the question of optimal load shifting and scheduling using a limited capacity [35][36].

\section{Stochastic Dynamic Programming (SDP)}

\section{Overview of Dynamic Programming}

A great method to find optimal control solutions is to use DP. This solution is almost never casual because we need to know future disturbances or changes in advance. However, if these are known there is a strong case for using DP to find an optimal solution. In a typical deterministic DP; at each stage, decisions are ranked based on the summation of present cost and expected future cost, assuming optimal decision making for subsequent stages [32].

The symmetric part of the problem shown in fig. 2 can be successfully dealt in this manner. When the stochastic element is taken into account, DP methods can be evolved to solve them in an effective way [37]. Moreover, the cost model we have in equation (8) is similar to a Markov process because decisions are only based on the current state and the future but not any past decisions.

A typical DP is shown in the next few equations based on the definitions and algorithm in [38].

The structure of the problem in DP format can be described for a discrete-time system:

$$
x_{k+1}=F_{k}\left(x_{k}, u_{k}\right) \text { where } k=0,1, \ldots, N-1 \text { (time-steps) (9) }
$$


Here, $x_{k}$ is the state which uses information from the previous step for future optimization, $u_{k}$ is the control variable which is the decision to be made. $N$ is the size of control applications. This leads to a costfunction which is additive over time:

$$
J_{\pi}=E\left\langle F_{N}\left(x_{N}\right)+\sum_{k}^{N-1} F_{k}\left(x_{k}, u_{k}\right)\right\rangle
$$

Here $\pi$ is the control policy- $\pi=\left\{\mu_{0}, \mu_{1}, \ldots, \mu_{N-1}\right\}$, where $\mu_{k}$ is the control for state $x_{k}$

For initial state $x_{0}$, expected cost of $\boldsymbol{\pi}$ will be given as:

$$
J_{\pi}\left(x_{0}\right)=E\left\langle F_{N}\left(x_{N}\right)+\sum_{k=0}^{N-1} F_{k}\left(x_{k}, \mu_{k}\left(x_{k}\right)\right)\right\rangle
$$

The optimal control policy $\boldsymbol{\pi}^{\mathbf{0}}$ is the policy that minimizes $J_{\pi}$ for $k=$ $0,1, \ldots, N-1$

$$
J^{0}\left(x_{0}\right)=\min _{x \in S} J_{\pi}\left(x_{0}\right)
$$

Where $S$ is the set of all admissible policies.

If we assumed a random stochastic element $d$ that affects the states, (11) becomes:

$$
J_{\pi}\left(x_{0}\right)=E\left\langle F_{N}\left(x_{N}\right)+\sum_{k=0}^{N-1} F_{k}\left(x_{k}, \mu_{k}\left(x_{k}\right), d\right)\right\rangle
$$

The definition of $\mathrm{d}$ depends on the specific problem and the probability density function applied to the disturbance. There are some assumptions central to this theory: the set of values which control the input $u_{k}$ depend on the state only at $\mathrm{k}$ (Markov property) and not on previous steps; the information from the previous step is used in determining the current state value and the probability distribution of $d$ does not depend on itself at other time steps (i.e. time-invariant) but depends on state $x_{k}$ and input $u_{k}$.

\section{DP algorithm for the EV charging problem}

The most promising method, has shown to be a modified algorithm of dynamic programming (DP) presented in [37]. The DP function solves discrete-time optimal control problems using Bellman's DP algorithm. The work done in this paper by ETH Zurich affiliated Sundstrom and Guzella, describes a generic DP MATLAB function. This proved to be a good starting point as they have shown their function to be applicable to a hybrid EV energy management system.

The charging problem described in the current paper is different, therefore the function had to be significantly customized and recoded with the stochastic computational elements added to the overall program. The final code for the controller simulation is quite different and is based on the algorithms explained here, and in the SDP algorithm section. Although this function is specific to the EV charging problem, as a matter of another study it could be modified to fit any Stochastic Dynamic Program.

The following inputs are defined for the algorithm
Algorithm 1: Deterministic Dynamic Programming

- State: $\boldsymbol{x}$ (here $X_{1}-$ SoC and $X_{2}$ - grid-cost)

- Control: $\boldsymbol{u}$ (here Charge Power)

- $\quad$ Grid size for all states

- Model functions: $\mathrm{f}$ and $\mathrm{c}$ here:

$$
\begin{gathered}
x_{1, k+1}=x_{1, k}+\mathrm{u}_{\mathrm{k}} \\
\mathrm{x}_{2, \mathrm{k}+1}=\alpha x_{2, k}+\beta_{k} \\
c_{k}=x_{2, k}+R u^{2}
\end{gathered}
$$

- Final state cost: $J_{N+1}^{*}$ for all states $\boldsymbol{x}_{k+1}$ on the grid (here: $J_{N+1}=c_{N+1}\left(x_{N+1}\right) \times k$, where $c_{N}$ is the distance from the admissible set, and $k$ is a penalty factor)

- Time horizon: $\mathrm{N}$

1. State and input grids are created from discretization limits

2. Iterate over the time horizon backwards $k=N \ldots 1$

2.1 For each state $x_{k}$ 2.1.1 For each input $\boldsymbol{u}_{k}$

$$
\begin{aligned}
& \text { 2.1.1.1 Evaluate the Model: } \\
& x_{k+1}=f\left(x_{k}, u_{k}\right) \\
& c_{k}=c\left(x_{k}, u_{u}\right)
\end{aligned}
$$

\subsubsection{Interpolate the remaining cost}

$J_{k+1}^{*}\left(x_{k+1}\right)$ based on $x_{k+1}$ and the cost at the state grid points.

\subsubsection{Calculate the total cost}

Based on the step cost and the remaining cost

$$
J_{k}\left(x_{k}, u_{k}\right)=c_{k}\left(x_{k}, u_{k}\right)+J_{k+1}^{*}\left(x_{k+1}\right)
$$

2.1.2 Find the best input $u_{k}^{*}\left(x_{k}\right)$ that produces the lowest $\operatorname{cost} J_{k}\left(x_{k}, u_{k}^{*}\right)=J_{k}^{*}\left(x_{k}\right)$

2.2 A cut-off grid-cost line is mapped for visualization purposes. This is the grid cost for a given state of charge at which the charging power reaches $50 \%$. (optional)

Once the ideal control strategy has been found, it is simulated to find the projected cost.

Algorithm 2: Optimal Charging Simulation

1. For the forward simulation, define the initial state $x_{1}$

2. Iterate over the time horizon forwards $k=1 \ldots N$

2.1 Evaluate the model

$$
x_{k+1}=f\left(x_{k}, u_{k}^{*}\left(x_{k}\right)\right)
$$




\section{SDP version of the Algorithm}

The previous algorithm successfully describes the dynamic programming stage for the deterministic part (fig.2). The stochastic element is now included in the algorithm, however as will be seen it is computed prior to the DP stage (fig.3). The advantage of this approach is that it makes the final algorithm elegant and computationally less intensive. It can achieve this because it essentially isolates the stochastic element; thus not having it calculated in every single nested iteration.

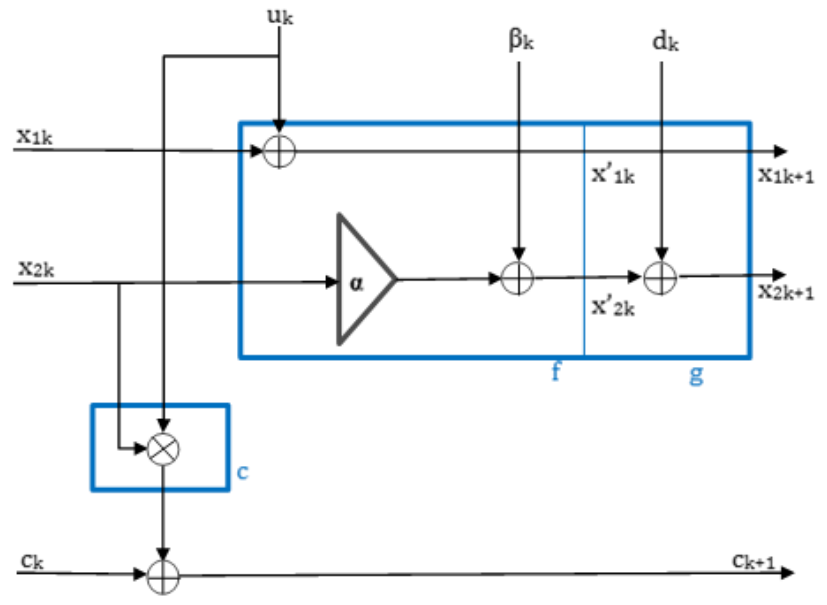

Figure 3: Charging controller with functions

Regarding state $\mathrm{X}_{2}$

If at time-step say, $k$ we define the stochastic state as $x_{k}^{\prime}$, the function is:

$$
x_{k}^{\prime}=g\left(x_{k}, d\right)
$$

Here, $x_{k}$ is the deterministic state of grid-cost and as known $d$ is the stochastic disturbance. If, the deterministic function is $f$, the fig.2 becomes as above.

The algorithm can now be rewritten as follows.

Algorithm 3: Stochastic Dynamic Programming

- State: $\boldsymbol{x}$ (here $X_{1}-$ SoC and $X_{2}-$ grid-cost)

- Control: $\boldsymbol{u}$ (here Charge Power)

- Grid size for all states

- Model functions: $\mathrm{f}$ and c here:

$$
\begin{gathered}
x_{1, k}^{\prime}=x_{1, k}+\mathrm{u}_{\mathrm{k}} \\
\mathrm{x}_{2, \mathrm{k}}^{\prime}=\alpha x_{2, k}+\beta_{k} \\
c_{k}=x_{2, k}+R u^{2}
\end{gathered}
$$

- $\quad$ Final state cost: $J_{N+1}^{*}$ for all states $\boldsymbol{x}_{k+1}$ on the grid (here: $J_{N+1}=c_{N+1}\left(x_{N+1}\right) \times k$, where $c_{N}$ is the distance from the admissible set, and $k$ is a penalty factor)
- The stochastic model $\mathrm{g}$ here:

$$
\begin{gathered}
x_{1, k+1}=x_{1, k}^{\prime} \\
\mathrm{x}_{2, \mathrm{k}+1}=x_{2, k}^{\prime}+d_{k}
\end{gathered}
$$

- Time horizon: $\mathrm{N}$

1. State and input grids are created from discretization limits

2. Iterate over the time horizon backwards $k=N \ldots 1$

2.1 The expected cost function using the stochastic function $\mathrm{g}$ is calculated

$$
J_{k}^{\prime}\left(x_{k}^{\prime}\right)=E\left\langle J_{k+1}^{*}\left(x_{k+1}\right)\right\rangle
$$

\subsection{For each state $x_{k}$}

\subsubsection{For each input $\boldsymbol{u}_{k}$}

$$
\begin{array}{ll}
\text { 2.1.1.1 Evaluate the Model: } & \\
& x^{\prime}{ }_{k}=f\left(x_{k}, u_{k}\right) \\
& c_{k}=c\left(x_{k}, u_{u}\right)
\end{array}
$$

\subsubsection{Interpolate the remaining cost}

$J_{k}^{\prime}\left(x^{\prime}{ }_{k}\right)$ Based on $x^{\prime}{ }_{k}$ and the cost at the state grid points.

\subsubsection{Calculate the total cost}

Based on the step cost and the remaining cost

$$
J_{k}\left(x_{k}, u_{k}\right)=c_{k}\left(x_{k}, u_{k}\right)+J_{k}^{\prime}\left(x_{k}^{\prime}\right)
$$

2.1.2 Find the best input $u_{k}^{*}\left(x_{k}\right)$ that produces the lowest cost $J_{k}\left(x_{k}, u_{k}^{*}\right)=J_{k}^{*}\left(x_{k}\right)$

2.3 A cut-off grid-cost line is mapped for visualization purposes. This is the grid cost for a given state of charge at which the charging power reaches $50 \%$. (optional)

Once the ideal control strategy has been found, it is simulated to find the projected cost using Algorithm 2.

\section{Controller}

\section{Overview}

The SDP controller can be termed as the 'decision-module' in the system shown in figure 4. It uses the algorithm discussed to make the decision 'to charge or not' on the basis of: event-probability $\left(\mathrm{P}_{\mathrm{ev}}\right)$, decay factor $(\alpha)$ and cost-disturbance $(\beta)$ all of which are predicted from annual data of day ahead prices (DAP) or real time prices (RTP) for any electricity grid.

This paper explains the SDP controller and discusses simulation results. The statistical stochastic predictor is scientific work to be done in the future which will help investigate the approach to obtain realistic values for constants like $\alpha, \beta$ and $\mathrm{P}_{\mathrm{ev}}$. 


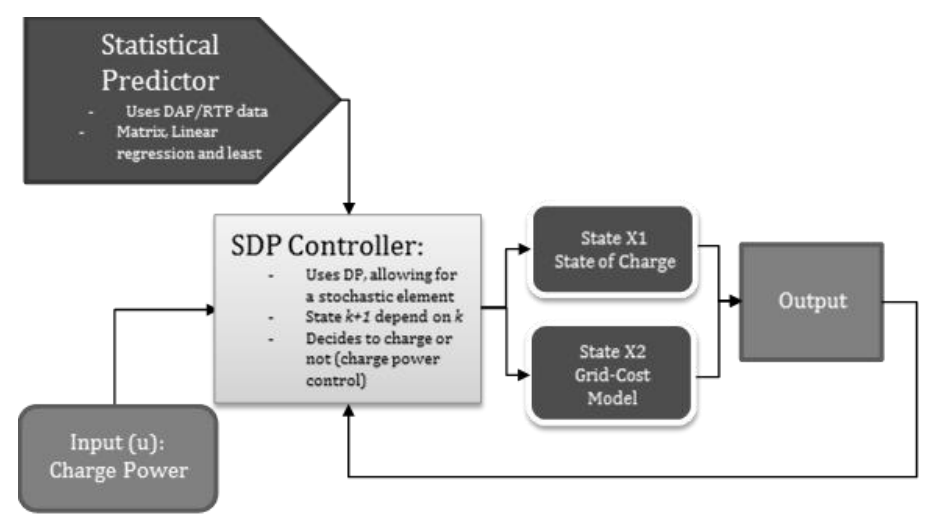

Figure 4: System Idea Overview

\section{Assumptions}

The simulation which was performed to test the controller is based on some assumptions. The aim here is to test the controller's basic function: its decision ability to pick the best hours to charge by using a prediction for price changes.

A DAP profile for an arbitrary evening is selected from the Amaren tariffs for Illinois, Chicago, USA [39]. A hypothetical event is triggered (or not triggered) to test the controller's reaction in different scenarios.

- $\quad$ The grid model described is a Markov process and uses basic principles for price changes

- $\quad$ The decay factor $(\alpha)$, disturbance ( $\beta$ ) and price-event change are all assumed as constant for simulation (stated in each scenario results)

- $\quad$ The $\mathrm{P}_{\mathrm{ev}}$, probability that an event might occur is selected constant and arbitrary for simulation; to help verify the controller functioning in different probability situations

- The grid model function is mostly linear

- Battery losses are represented by multiplying or adding simple penalties to the final cost

- The EV specifications are all assumed to have no effect on charging, the controller is tested for a 14 hour charging situation where the user reaches home and plugs in the vehicle at 5:00pm and requires the vehicle by 7:00am

- The user is requesting a (0.8 x battery power) $80 \% \mathrm{SoC}$ by 7:00am

- $\quad$ EV battery temperature, ambient temperature effects are not taken into account

- The charge power is represented as a fraction of the battery power $(u)$

- Charging power is assumed to be 'fast-charge' when using more than 0.2 times $\mathrm{x}$ battery power

- DAP information has been received by the controller via a smart-grid connection prior to or as soon as the vehicle is plugged in

\section{Results}

\section{Basic Scenario}

The baseline scenario provided to the controller assumes fastcharging at $(0,5 x$ batt power $)$ and no resistive losses. Different cases are explored in this scenario to see the decisions the controller makes and this tests the SDP output.

\section{NO EVENT}

Table 1 shows the input parameters: for the first baseline case, we discuss the results for price-selection, charge-decision, optimal-control map, cost-of-control decision and a snapshot of the cut-off prices. There is a positive event probability but no price-event for the first case.

\section{Table 1: Input Parameters for Basic Scenario}

\begin{tabular}{|c|c|}
\hline & Current Parameters \\
\hline Time Step & 1 \\
\hline Number of Hours & 14 \\
\hline Alpha & 0.8 \\
\hline Charge Power & 0.5 \\
\hline Resistive Penalty & 0 \\
\hline Event Probability & 0.1 \\
\hline Event Time & None \\
\hline
\end{tabular}

Figure 5 shows, the controller decides to start charge at 21:00 (allowing full power at 22:00) and realizes it may need lesser time than initially calculated to charge. The charge power drops after 22:00 and a full charge is achieved by 00:00. What is of importance here is that the SDP controller picks a slightly higher cost than the lowest possible in the 14 hours. This is because it has a positive event probability and it decides it is better to provide a 'full' charge at a minimal penalty (low enough cost at 22:00) than to wait for the lower cost (at a later hour) and risk having to charge during a price-event. It therefore predicts an event and prefers to pick a low enough price to charge 'and' provide required SoC by 07:00.
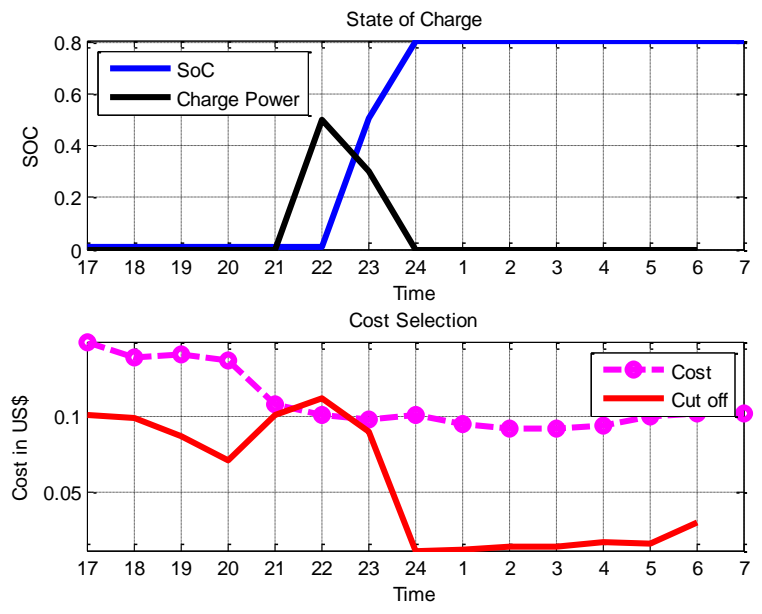

Figure 5: Controller output for Base Scenario 


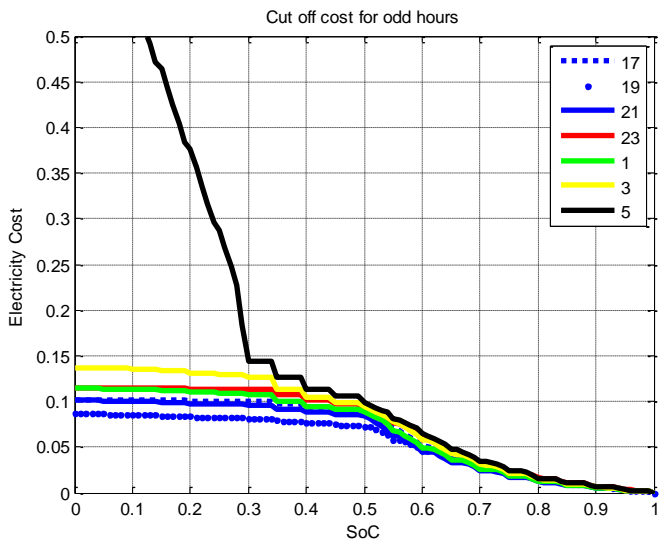

Figure 6: Cut-off Cost Trajectories

This shows that with a probability of an event occurring at ( $\mathrm{Pev}=0.1)$, the controller works intelligently to provide a full charge (which is a boundary condition $\mathrm{E}=\mathrm{E}_{\text {full }}$ ) whilst picking the lowest possible cost trajectory to follow in the process. This can be seen in the cut-off cost plot: a higher cut-off cost is being preferred between 20:00 and 00:00, initially this is because of the probability and later this cut-off falls because the SoC increases and less time is needed to complete the goal; it can risk and wait to find a lower cost.

Figure 6 shows the cut off cost selection for odd hours for the 14 hour time period. It is visible that as time passes and SoC has not been met, the controller is ready to pick a higher cost to make sure charge is provided in time. When possible, the lowest cost is chosen proving that the controller works to provide 'the optimal cost charging' within the set parameters (SoC and $\mathrm{ToC}$ ) by predicting an event based on probability.
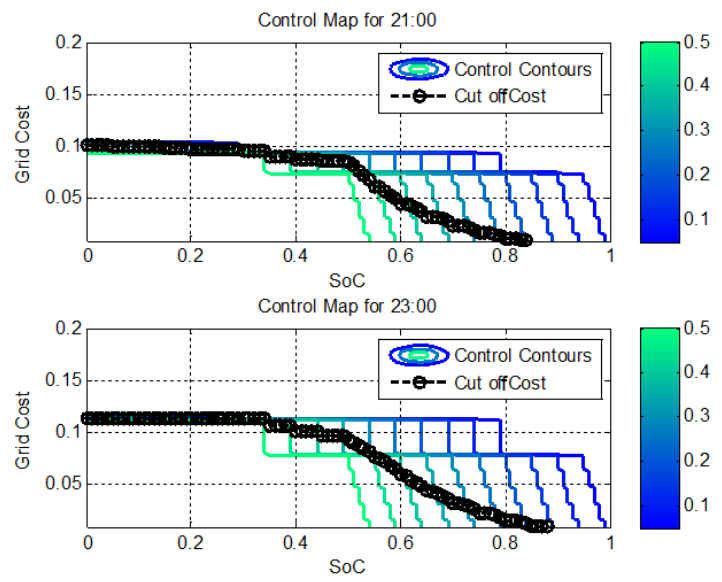

\section{Figure 7: Controller Maps Base Scenario}

Figure 7 shows a snapshot of the optimal control map where the colourbar represents charge power for 21:00 and 23:00 (covers one charge decision and one discharging decision for this scenario). The selection of the cost is logical as seen here: The charge power is increased if the cost and SoC are lower. As both increase, charge power is decreased. In this case the most important area is between 0 and $37 \%$ SoC, where the decision to charge or not falls within a small range of grid-cost. The map suggests that once the cost is near $\$ 0.1$, the Page 9 of 14 controller will charge because the cost before is very high and $\$ 0.1$ is a low-enough cost to pick and charge to achieve full SoC. The black line follows the trajectory of the cost cut-off decision which shows risking to wait for a lower-cost as battery charge increases. At 23:00 time has passed (SoC has increased), the controller selects to lower charge power, getting ready to wait for a lower cost but it is low enough to continue charging and not risk an event (because of probability).

Figure 8 shows the map of cost (of control decision) at 17:00. The colourbar indicates the cost of control. The plot shows that cost is proportional to the SoC missing in the battery. The cost of use is only low if the grid-cost is low and $\mathrm{SoC}$ is higher, otherwise the controller has to charge to provide $\mathrm{E}=\mathrm{E}_{\text {full }}$ at a higher cost.

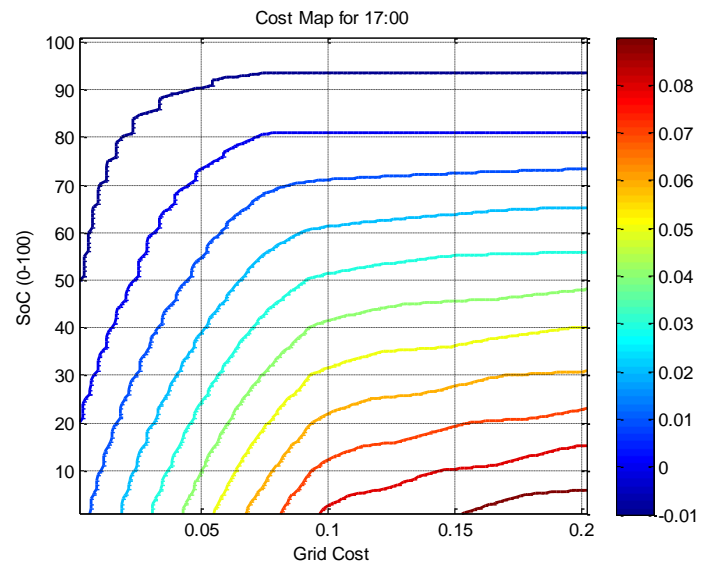

Figure 8: Cost (J) map for 17:00

\section{NO PROBABILITY}

Figure 9 shows the controller reacting very differently. It does not rush to charge but waits until the price is much lower because it predicts no events. It picks the lowest hours to charge at full power provided it can give a full charge in the remaining hours. This is evident in the plot as the cut-off costs become higher as time passes, until the battery charge is higher. This reinforces the requirement for accurate probability values to be passed from the predictor.
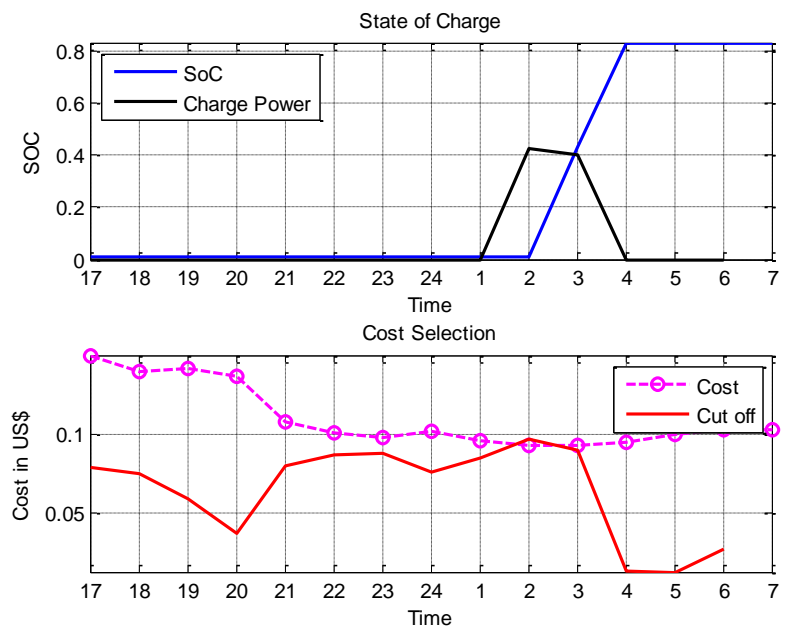

Figure 9: Controller output with $\mathrm{Pev}=0$ 


\section{EVENTS}

Table 2 shows the input parameters: There is a positive event probability and early, middle, late hours and long events. The reactions of the controller in each case are compared.

\section{Table 2: Input Parameters for base scenario events}

\begin{tabular}{|c|c|}
\hline & Current Parameters \\
\hline Time Step & 1 \\
\hline Number of Hours & 14 \\
\hline Alpha & 0.8 \\
\hline Charge Power & 0.5 \\
\hline Resistive Penalty & 0 \\
\hline Event Probability & 0.1 \\
\hline Event Time & $3,6,12,6+$ \\
\hline
\end{tabular}

Figure 10 shows the early event case; at 20:00 the price event occurs and alters the trajectory for future hours. The controller detects this, avoids the event and the increased prices until 00:00. The prices have started falling and reach low enough at 1:00 to warrant a charging phase to complete the charge. The cut-off prices increases (therefore, the need to charge in any cost situation) after 00:00 because the ToC is nearing with no charge in the battery. The controller successfully picks low price hours till 3:00 to charge leaving no risk for later in case there is another event.
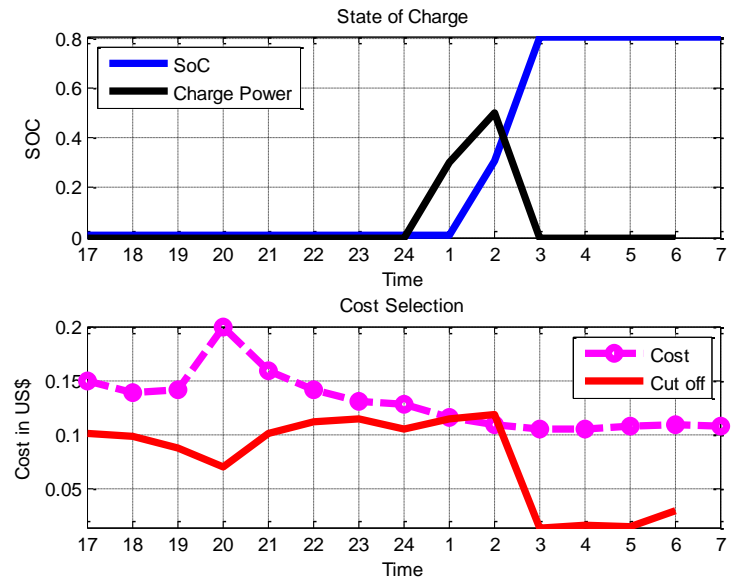

Figure 10: Early Event (base)

Figure 11 shows the middle event case; the controller sees a low price point at 21:00-22:00 where it decides to charge but an event occurs and changes the cost significantly after 22:00. The controller predicts and stops charging before the price reaches a high at 23:00. The battery is $50 \%$ charged by then so it waits for a very low cost until 3:00-4:00 when it decides to charge again to provide $\mathrm{SoC}$ as required. In the second charge phase it does not use all the charging power (only 0.3 compared to 0.5). This shows it meets the goals of avoiding high demand and cost, but still provides a full charge by ToC.
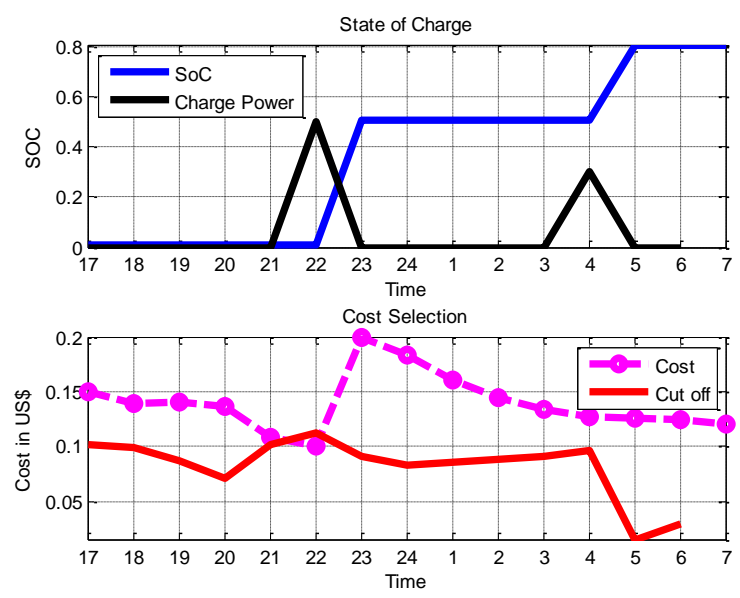

Figure 11: Middle Event (base)

Figure 12 shows the late event case; here the controllers picks to charge almost exactly like the no event case in Figure 5. This proves that it predicts the possibility of an event due to the positive Pev and decides to charge with a minimal penalty, to be safe and provide SoC at ToC. Only, in this case, the prediction is right and there is an event at hour 12 , changing the costs quite significantly.
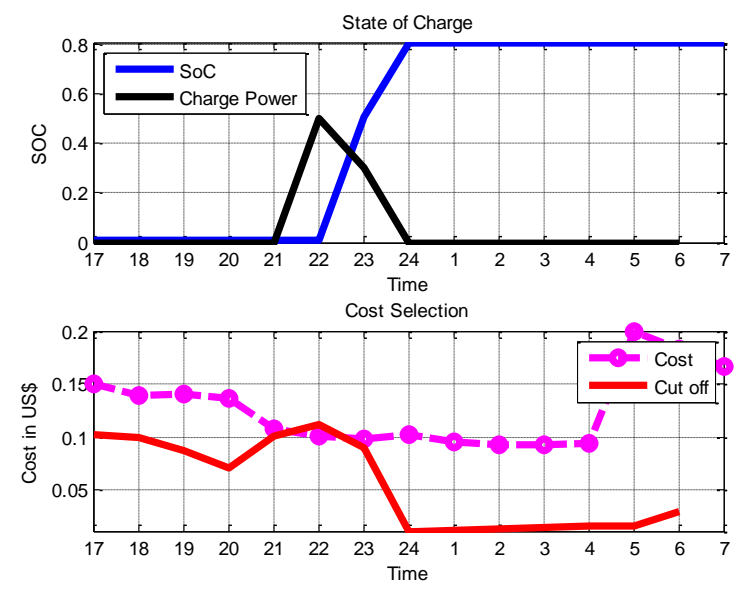

Figure 12: Late Event (base)

Figure 13 describes the long event case; initially the controller behaves similarly to the middle event case, where it charges between 21:00 till the event alters the costs. It then stops and waits for a time of low cost to try and save both demand and price. However, the event continues to keep the prices high all through the remaining hours and the controller panics at 5:00 because the battery is not charged. It decides to charge bearing the penalty in order to provide $\mathrm{SoC}$ at ToC. The cut off cost trajectory shows this decision behavior, as it keeps increasing the risk cost because $\mathrm{SoC}$ has not been met as the hours pass. 

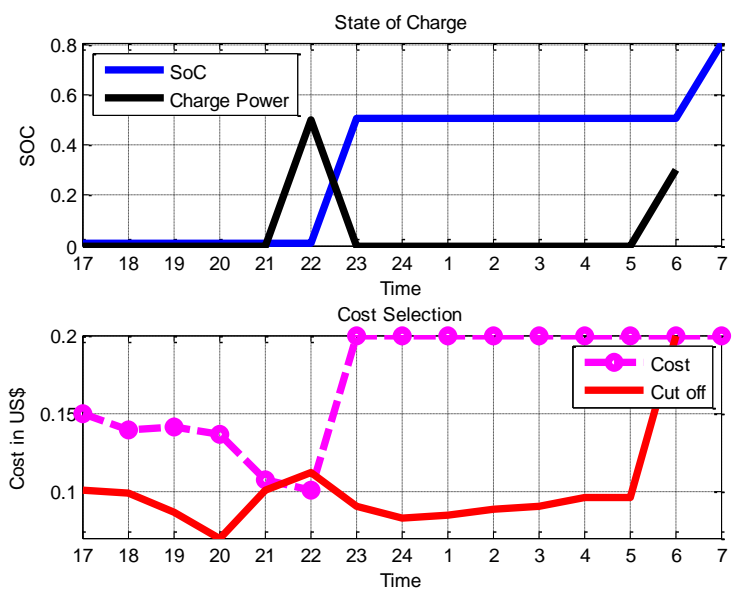

Figure 13: Long Event (base)

\section{Scenario with Resistive Losses}

Scenario 2 provided to the controller aims to analyse the decisions in a little more realistic situation where the resistive battery losses affect the charging power. The obvious implication is that as losses affect charge power, it will take longer to finish charging, so the predictions and decisions will change accordingly.

Table 3: Parameters for Scenario with Losses

\begin{tabular}{|c|c|}
\hline & Current Parameters \\
\hline Time Step & 1 \\
\hline Number of Hours & 14 \\
\hline Alpha & 0.8 \\
\hline Charge Power & 0.5 \\
\hline Resistive Penalty & 0.03 \\
\hline Event Probability & 0.1 \\
\hline Event Time & 6 \\
\hline
\end{tabular}

Figure 14 shows that the controller decides to charge at the low price point at 21:00. It starts to provide charge after 20:00 and more power by 22:00 when price is even lower but the power is clearly affected by the resistive losses and effectively reaches only a value of 0.3 . The event occurs at 22:00 and the price shoots up, the controller stops charge and waits. Unlike the choice in scenario without resistive losses (Figure 11), the controller picks a slightly higher price at 2:00 because more time is needed to charge owing to low net charge power. This proves the intelligence in the controller works both for picking a low cost and compensating for losses. This can also be seen in the cut-off cost trajectory, where the risk cost is higher at 2:00.
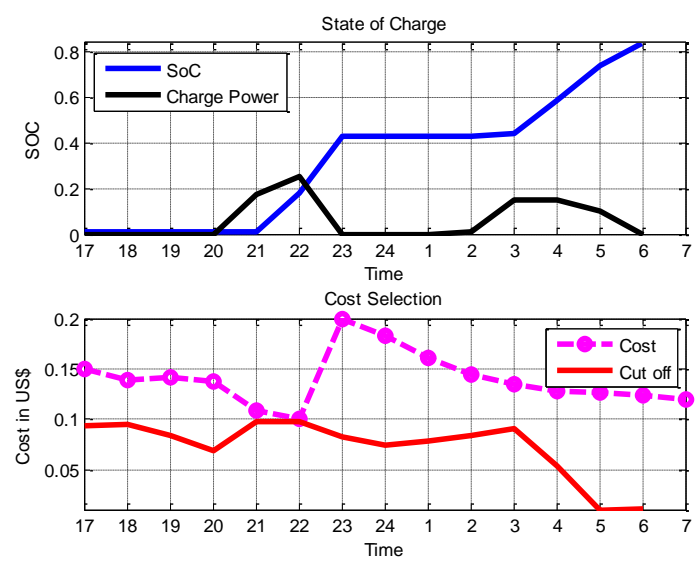

Figure 14: Controller output with Resistive Losses

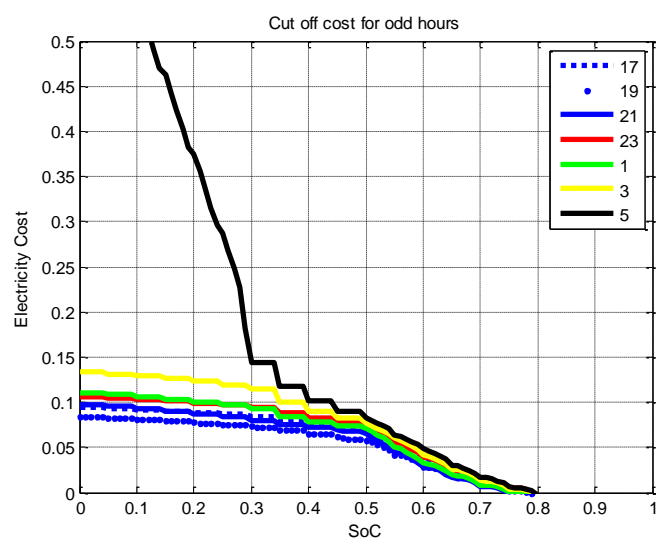

Figure 15: Cut-off cost trajectories for Losses

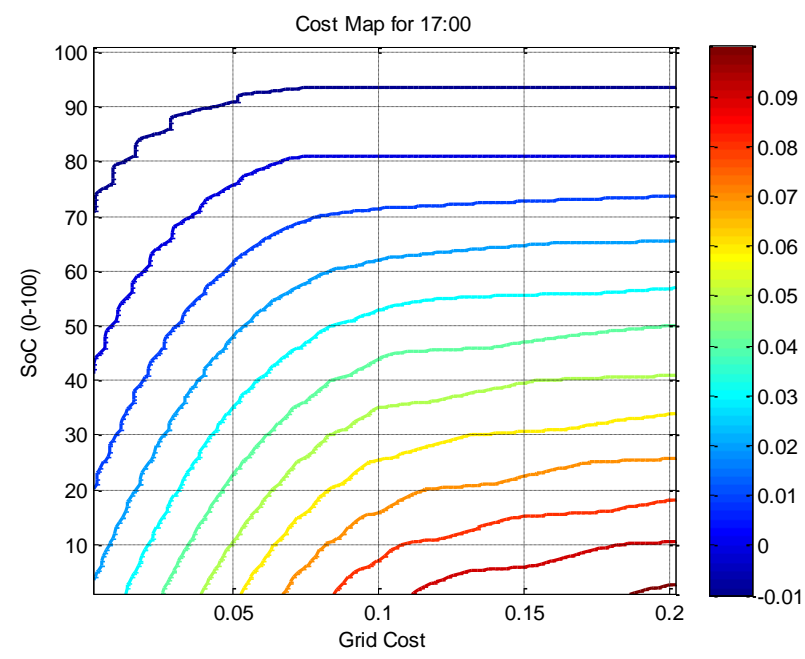

Figure 16: Cost (J) Map for 17:00

The cost of control map in Figure 16 also reflects this change. It indicates clearly that the controller is ready to accept higher penalties to finish the job. This scenario and the reaction to it shows that in reality, with losses taken into account, any controller will have to make 
compromises but the SDP controller makes these whilst still striving to find the lowest possible expense.
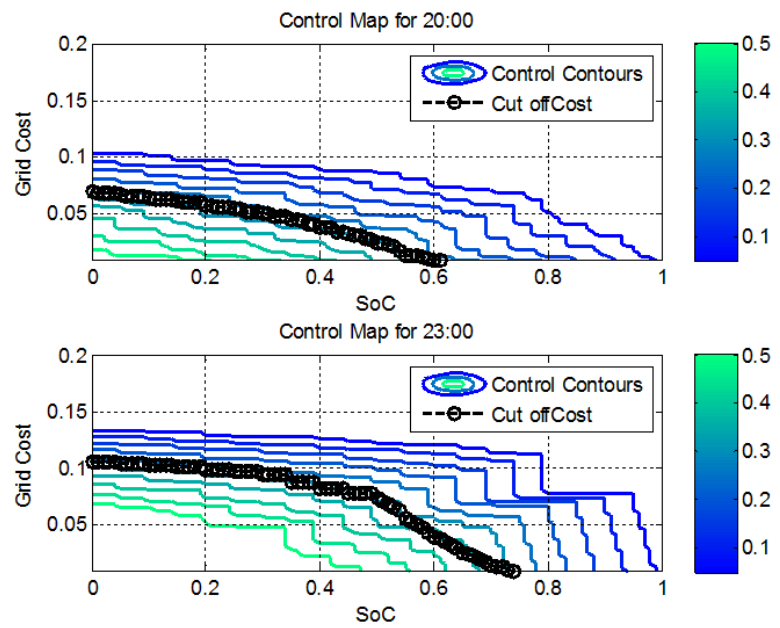

Figure 17: Controller Map for Losses

Figure 17 shows the optimal controller map for this scenario which differs significantly from the base shown in Figure 10-13. The price range at low $\mathrm{SoC}$ is much wider in this case, which is forced by lower net power due to losses. The controller has to compensate for this to provide the required full $\mathrm{SoC}$ on time. Proving once again that it will always meet the most important goal of finishing the charge.

\section{Scenario using Slow Charging}

Scenario 3 tries to explore the slow charging base scenario without resistive losses. The obvious implication is that with lower charge power, battery will need more time to charge, so the strategy will have to be altered accordingly.

\section{Table 4: Input Parameters for Scenario 3}

\begin{tabular}{|c|c|}
\hline & Current Parameters \\
\hline Time Step & 1 \\
\hline Number of Hours & 14 \\
\hline Alpha & 0.8 \\
\hline Charge Power & 0.2 \\
\hline Resistive Penalty & 0 \\
\hline Event Probability & 0.1 \\
\hline Event Time & $3,6,12$ \\
\hline
\end{tabular}

Figure 18 shows the middle event case; 21:00 has a lower cost and just like in the cases the controller decides to charge but encounters an event at 22:00. As the charging stops, the SoC achieved is lower compared to fast-charge scenarios. Figure 18, 19 both show the cut-off cost trajectories which describe the risk selections are much higher to compensate. The controller waits until 2:00 but takes the penalty of the higher costs (compared to 4:00) to be safe and provide charge. Figure 19 shows a very different plot compared to other cases; here at 3:00 as well as 5:00 the cut -off values are much higher for the range of SoC, indicating the willingness to accept penalties if the $\mathrm{SoC}$ is too low.
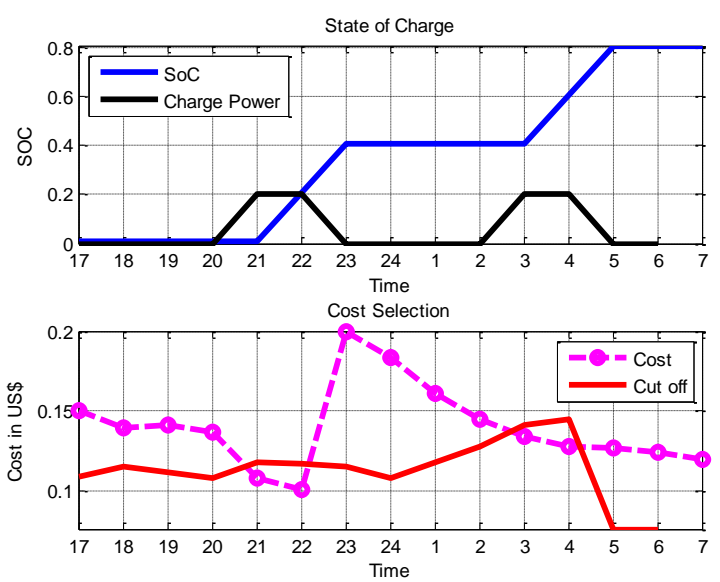

Figure 18: Controller output for slow charge

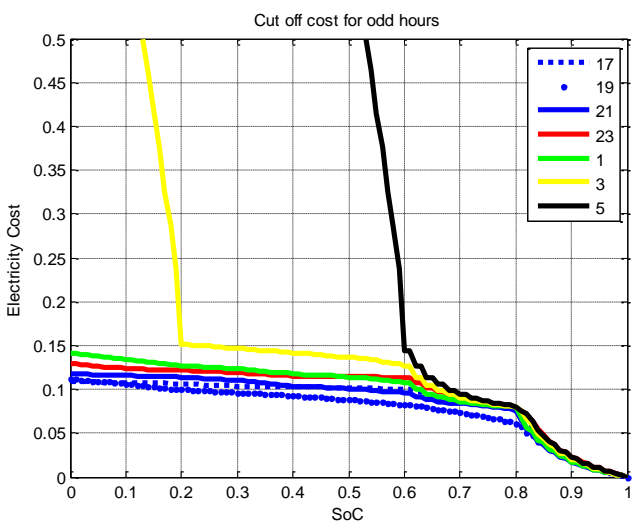

Figure 19: Cut-off Trajectories for slow charge

Figure 20 shows the strategy for the case with an early event. As the event really causes a high in the early hours, the controller completely avoids charging and waits for a really low cost. At 00:00, it picks a low cost but predicts a possible event later and for safety begins charging. It continues to provide power as the costs only fall over the period and provide SoC by 5:00. The cut-off cost penalties increase all the way through 20:00 to 3:00 (where the battery achieves 50\% SoC).
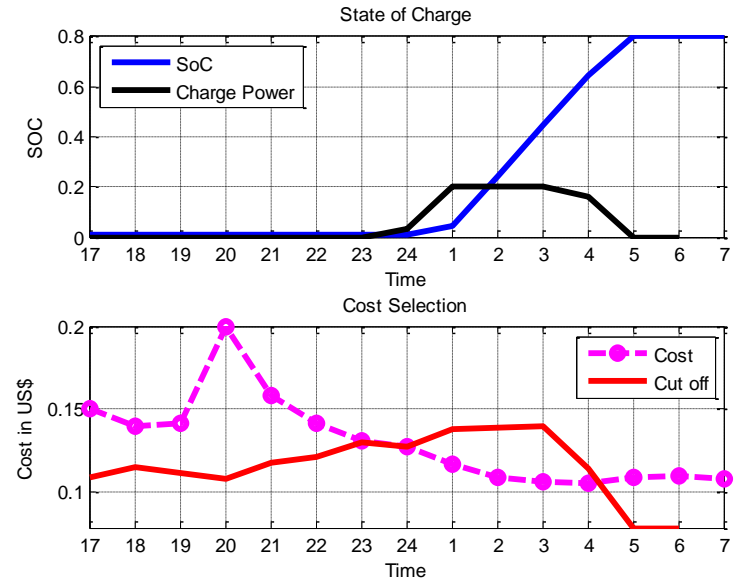

Figure 20: Slow Charge with early event 
Figure 21 shows a late event case; here the controller predicts an event because of the positive Pev. So, it picks a low enough cost at 20:00 and provides full power at 21:00 when the cost is low. It charges till 00:00, when the cost jumps a little; it stops charging and waits. The next hour, the cost falls again and the controller charges at full power and achieves SoC quickly. The event that occurs at 4:00, is therefore avoided completely by the controller's strategy.
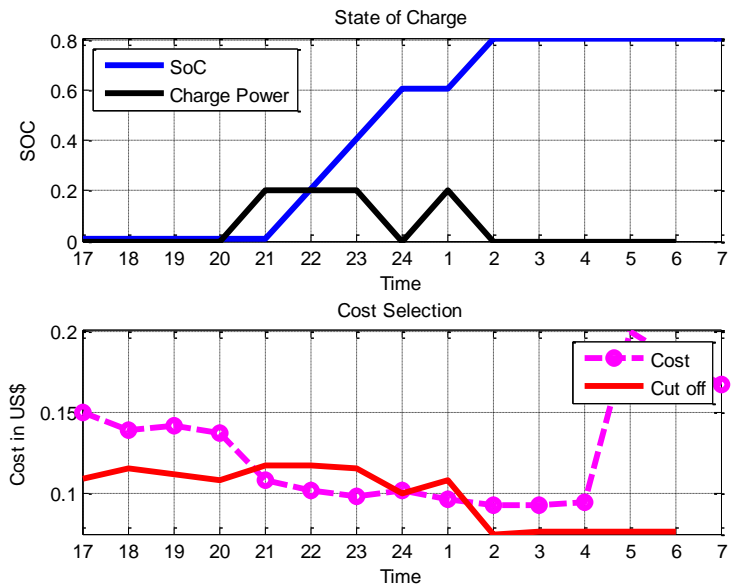

Figure 21: Slow charge with late event

\section{Conclusions}

The paper presented takes the basic EV charging problem and explains the dynamic side of it. The stochastic nature of the problem is realized and a better and optimal solution is presented compared to the suboptimal controller presented in [13]. The optimal controller uses a time-discrete stochastic optimization within a dynamic program. The MATLAB controller function is a significantly elaborate yet based on a simple and functional algorithm. The controller takes into account the required SoC and ToC (user-defined) and controls charging over the provided time period (and time period data). It successfully predicts possible price-events ('spikes') and compensates to charge the battery at lower cost hours. The main goal of the control is to provide required $\mathrm{SoC}$ in time, which it attempts to achieve by selecting the lowest possible costs. It is intelligent enough to make compromises and charge at penalty prices if required for SoC at ToC. The SDP controller is a large improvement over the sub-optimal solution presented before. The old controller could not predict price changes but simply reacted to DAP data provided by a smart-grid.

The prediction ability of the controller has been tested using simulation of a 14hour period of an arbitrary evening in the year. Testing scenarios included positive and no event probabilities, effect of resistive losses and a lower charge power. In each case, the controller behaves as expected and not only predicts possible price jumps but also reacts to them in a 'safe' manner thus being able to provide SoC and not leaving the user stranded. In all cases it picks lower costs than otherwise if the charging was performed arbitrarily (for example: as soon as the EV is plugged in). The results comprehensively prove this as an optimal solution, where the EV would charge automatically saving costs and in turn offsetting high demand. We conclude that the next step is to subject this controller to a case-study based on an accurate prediction system (dubbed statistical predictor fig.4) for the constants (especially price-disturbance $\beta$ ) used in the current paper. This system would use annual DAP and RTP data and analyze it to provide predicted values for any day of the year, for disturbance and 'event' probability.

\section{References}

[1] A. Zubaryeva, C. Thiel, E. Barbone, and A. Mercier, "Assessing factors for the identification of potential lead markets for electrified vehicles in Europe: expert opinion elicitation," Technol. Forecast. Soc. Change, pp. 1-16, Jul. 2012.

"World energy outlook 2009," IEA (International Energy Agency), Paris, 2009.

J. E. Kang and W. W. Recker, "An activity-based assessment of the potential impacts of plug-in hybrid electric vehicles on energy and emissions using 1-day travel data," Transp. Res. Part D Transp. Environ., vol. 14, no. 8, pp. 541-556, Dec. 2009.

"Nearly $20 \%$ of U.S. cars will be hybrids by 2020 , forecast says," Automotive News, 2009.

P. Bauer, Y. Z. Y. Zhou, J. Doppler, and N. Stembridge, "Charging of electric vehicles and impact on the grid," MECHATRONIKA, 2010 13th Int. Symp., 2010.

K. Clement-Nyns, E. Haesen, and J. Driesen, “Analysis of the impact of plug-in hybrid electric vehicles on residential distribution grids by using quadratic and dynamic programming," World Electr. Veh. J., vol. 3, 2009.

[7] J. Meyer, S. Hähle, P. Schegner, and C. Wald, "Impact of electrical car charging on unbalance in public low voltage grids," in Proceeding of the International Conference on Electrical Power Quality and Utilization, EPQU, 2011, pp. 635-640.

[8] P. Stroehle, S. Becher, S. Lamparter, A. Schuller, and C. Weinhardt, "The impact of charging strategies for electric vehicles on power distribution networks," in 2011 8th International Conference on the European Energy Market, EEM 11, 2011, pp. 51-56.

[9] L. Zhang, T. Brown, and G. S. Samuelsen, "Fuel reduction and electricity consumption impact of different charging scenarios for plug-in hybrid electric vehicles," J. Power Sources, vol. 196, pp. 6559-6566, 2011.

[10] H. Allcott, "Rethinking real-time electricity pricing," Resour. Energy Econ., vol. 33, no. 4, pp. 820-842, Nov. 2011.

[11] R. R. Pricing, "Bringing Residential Real-Time Pricing to Scale in Illinois : Policy Recommendations," pp. 2-5, 2009.

[12] E. N. A. (ENA), "DS 2030 Stakeholders Event," 2014.

[13] S. Mody and T. Steffen, "Optimal Charging of EVs in a Real Time Pricing Electricity Market," SAE Int. J. ..., 2013.

[14] K. Morrow, “U . S . Department of Energy Vehicle Technologies Program - Advanced Vehicle Testing Activity Plug-in Hybrid Electric Vehicle Charging Infrastructure Review," no. 58517, 2008.

[15] J. Wang, C. Liu, D. Ton, Y. Zhou, J. Kim, and A. Vyas, "Impact of plug-in hybrid electric vehicles on power systems with demand response and wind power," Energy Policy, vol. 39, no. 7, pp. 4016-4021, Jul. 2011.

[16] J. E. Kang and W. W. Recker, "An activity-based assessment of the potential impacts of plug-in hybrid electric 
vehicles on energy and emissions using 1-day travel data," Transp. Res. Part D Transp. Environ., vol. 14, no. 8, pp. 541-556, Dec. 2009.

[17] K. Clement, E. Haesen, S. Member, and J. Driesen, "Coordinated Charging of Multiple Plug-In Hybrid Electric Vehicles in Residential Distribution Grids," pp. 1-7, 2009.

[18] K. Parks, P. Denholm, and T. Markel, "Costs and Emissions Associated with Plug-In Hybrid Electric Vehicle Charging in the Xcel Energy Colorado Service Territory Costs and Emissions Associated with Plug-In Hybrid Electric Vehicle Charging in the Xcel Energy Colorado Service Territory," no. May, 2007.

[19] J. Mullan, D. Harries, T. Bräunl, and S. Whitely, "Modelling the impacts of electric vehicle recharging on the Western Australian electricity supply system," Energy Policy, vol. 39, no. 7, pp. 4349-4359, Jul. 2011.

[20] C. Weiller, "Plug-in hybrid electric vehicle impacts on hourly electricity demand in the United States," Energy Policy, vol. 39, no. 6, pp. 3766-3778, Jun. 2011.

[21] J. Druitt and W.-G. Früh, "Simulation of demand management and grid balancing with electric vehicles," $J$. Power Sources, vol. 216, pp. 104-116, Oct. 2012.

[22] a. P. Robinson, P. T. Blythe, M. C. Bell, Y. Hübner, and G. a. Hill, "Analysis of electric vehicle driver recharging demand profiles and subsequent impacts on the carbon content of electric vehicle trips," Energy Policy, pp. 1-12, Jul. 2013.

[23] G. Heydt, "The impact of electric vehicle deployment on load management strategies," IEEE Trans. Power Appar. Syst.;(United States), no. 5, 1983.

[24] R. Webster, "Can the electricity distribution network cope with an influx of electric vehicles?," J. Power Sources, vol. 80, no. 1-2, pp. 217-225, Jul. 1999.

[25] C. Camus and T. Farias, "Impacts of electric vehicles' charging strategies in the electricity prices," 2011 8th Int. Conf. Eur. Energy Mark., no. May, pp. 833-838, May 2011.

[26] M. Mahalik, L. Poch, A. Botterud, and A. Vyas, "Impacts of plug-in hybrid electric vehicles on the electric power system in Illinois," 2010 IEEE Conf. Innov. Technol. an Effic. Reliab. Electr. Supply, pp. 341-348, Sep. 2010.

[27] S. Acha, T. Green, and N. Shah, "Optimal charging strategies of electric vehicles in the UK power market," Innov. Smart Grid ..., pp. 1-8, 2011.

[28] T. K. Kristoffersen, K. Capion, and P. Meibom, "Optimal charging of electric drive vehicles in a market environment," Appl. Energy, vol. 88, no. 5, pp. 1940-1948, May 2011.

[29] R. A. Scholer, H. Mcglynn, and A. Llc, "Smart Charging Standards for Plug-In Electric Vehicles Price-Based Smart Charging," SAE Tech. Pap., 2014.

[30] K. Yunus, H. Z. De La Parra, and M. Reza, "Distribution grid impact of Plug-In Electric Vehicles charging at fast charging stations using stochastic charging model." pp. 111,2011

[31] J. Zheng, X. Wang, K. Men, C. Zhu, and S. Zhu, "Aggregation Model-Based Optimization for Electric Vehicle Charging Strategy," IEEE Trans. Smart Grid, vol. 4, no. 2, pp. 1058-1066, Jun. 2013.
[32] D. P. Bertsekas, Dynamic Programming and Optimal Control Vol I, II. Athena Scientific, 1995.

[33] A. Bemporad, L. Puglia, and T. Gabbrielline, "A stochastic model predictive control approach to dynamic option hedging with transaction costs," in American Control Conference, 2011, pp. 3862-3867.

[34] A. M. Thompson and W. R. Cluett, "Stochastic iterative dynamic programming: a Monte Carlo approach to dual control," Automatica, vol. 41, no. 5, pp. 767-778, May 2005 .

[35] L. Kuznia, B. Zeng, G. Centeno, and Z. Miao, "Stochastic optimization for power system configuration with renewable energy in remote areas," Ann. Oper. Res., no. March, pp. 123, 2011.

[36] A. Schroeder, J. Siegmeier, and M. Creusen, "Demand management and storage sizing in electricity distribution grids," 2011.

[37] O. Sundstr, "A Generic Dynamic Programming Matlab Function," no. 7, pp. 1625-1630, 2009.

[38] D. P. Bertsekas, Dynamic Programming and Optimal Control, 3rd ed. Athena Scientific, 2007.

[39] "Amaren Pricing Data." [Online]. Available: https://www2.ameren.com/retailenergy/realtimeprices.aspx.

\section{Contact Information}

Sagar Mody: S.Mody@lboro.ac.uk Thomas Steffen: T.Steffen@lboro.ac.uk

\section{Definitions/Abbreviations}

$\begin{array}{ll}\text { BEV } & \text { battery electric vehicle } \\ \text { DA } & \text { day-ahead pricing } \\ \text { HEV } & \text { hybrid electric vehicle } \\ \text { ICE } & \text { internal combustion engine } \\ \text { MPC } & \text { model (based) predictive control } \\ \text { RT/RTP } & \text { real time pricing } \\ \text { PHEV } & \text { plugin-in hybrid electric vehicle } \\ \text { SOC } & \text { (battery) state of charge } \\ \text { SD } & \text { standard deviation } \\ \text { V2G } & \text { vehicle to grid } \\ \text { EV } & \text { Electric vehicle } \\ \text { DP } & \text { Dynamic programming } \\ \text { SDP } & \text { Stochastic dynamic programming } \\ \text { ToC } & \text { Time of charge (required time) } \\ \text { SoC } & \text { State of charge (required) }\end{array}$

